\title{
El paradigma autista. Una hipótesis de trabajo \\ y una aproximación terapéutica
}

\section{G. Morandé; M. Peral}

Servicio de Psiquiatria y Psicologia Médica.

Sección de Psiquiatria Infantil.

Definimos el paradigma de funcionamiento autista como fóbicoparanoide, que a través de sus consecuencias genera el tipo de comportamiento propio del niño con este cuadro.

Teóricamente vemos una continuidad entre los aspectos paranoides y los fóbicos, más primitivos, inmaduros y/o patológicos, siendo los primeros más evolucionados que los segundos. En ambos hay una percepción alterada de la realidad y observamos una respuesta de temor o terror ante los estímulos externos y del propio sujeto. En el paradigma paranoide se pierde o no se alcanza al sentido de la realidad, la separación real del sujeto y los objetos percibidos, en el fóbico se mantiene más allá de la respuesta de ansiedad que genera.

La respuesta de ansiedad condiciona conductas de evitación o escape ante ella, comportamientos o mecanismos defensivos para otros autores, que variarán en su textura y amplitud según el grado de maduración del niño, el nivel de patología que presente o la situación ambiental a la que es sometido.

La evitación puede ir desde la anulación de conductas, el congelamiento similar al que vemos en aquellos animalitos cuya única defensa adaptativa es «hacerse» los muertos, ante otros mayores, hasta conductas de escape, fuga o estructuraciones complejas que permitan no enfrentar las situaciones temidas y alcanzar alguna acomodación al medio. Hablariamos entonces de un aprendizaje alterado, un comportamiento que se desarrolla por reforzamiento negativo. Por evitar el castigo o por disminuir la ansiedad el niño crea un repertorio que casi siempre nos parece raro, disarmónico e insuficiente. 
Partimos del supuesto de que, en la base de este funcionamiento, existe, en el niño autista, una predisposición biológica. Ignoramos cuál es ella y suponemos que existe una multicausalidad etiológica donde se mezclan factores constitucionales, agresiones al SNC durante el período de maduración de éste y eventos ambientales que favorecen el desencadenamiento del cuadro.

Existen similitudes entre el paradigma de desarrollo deficitario y el paradigma autista. Muchos de los casos estudiados deben necesariamente considerarse como mixtos. Aunque creemos que existan peculiaridades en el Síndrome Autista que le diferencian y que dan lugar a aquellos desarrollos propios del cuadro. No sabemos aún si esta diferencia está en la magnitud del problema biológico del niño o en la capacidad de adaptación precoz de los familiares a la fragilidad del sujeto.

Debe diferenciarse creemos, entre un funcionamiento deficitario de base y el concepto de deterioro, secundario a la falta de estimulación específica del medio o la presencia de noxas agresivas sobre el SNC cuando ya el desarrollo psicomotor ha alcanzado un cierto nivel. En el autista mayor podemos encontrar claros signos de deterioro.

\section{EL APRENDIZAJE POR EVITACION O LOS MECANISMOS DE DEFENSA EN EL NIÑO AUTISTA}

La presencia de la ansiedad como respuesta condicionada, en sujetos muy pequeños, incapaces biológicamente de integrarla (por inmadurez patológica o secundaria a la insuficiencia de la madre de dar la protección necesaria) desencadena en el niño una serie de alteraciones.

\section{La detención del desarrollo}

Es quizás el factor más significativo. El potencial de desarrollo de especie, tiende a detenerse en algún momento en el primero o segundo año de vida. En algunos casos retrocede incluso desde los patrones psicomotores ya alcanzados. En muchos casos este fenómeno es global, abarca todas las áreas, en otros se libran algunas funciones. La armonía se pierde. Los procesos de acomodación y asimilación en términos de Piaget se empobrecen terriblemente o se dan parcialmente y la conducta de buscar ávidamente refuerzos tanto en la acción como en las personas y objetos descritas por Popper se hace atípica, pobre y desconcertante para el observador o familiar.

En algunos casos la detención es tan global que en la observación fenomenológica parecería que no solamente la conducta se estanca, sino que la estatura, la distribución de las grasas, etc., nos hacen mirar un niño de 4 años que parece tuviera 18 meses. Quizá este dato, la edad que el niño sigue representando, constituirá un elemento adapta- 
tivo, para quienes trabajemos con él. Mientras menos edad parezca tener, más fácil nos será a los adultos cogerlo en brazos y hablarle y acariciarle como a un bebé. No todos los autistas se quedan pequeños, como el enano Oscar del Tambor de Hojalata. Otros continúan su desarrollo de forma disarmónica como luego veremos.

\section{La retracción autística}

Este signo (desde Kanner hasta Rimland) permanece como uno de los elementos centrales del cuadro. Puede ser uno de los primeros "descubrimientos» del autista. Es el congelamiento del animal acorralado que veíamos anteriormente. Es la anulación conductual o el terrible empobrecimiento de la conducta ante las personas y los objetos. Evita la'mirada, parece sordo, otras veces ciego. No pide ni con el gesto ni con la palabra, no anticipa ni con la sonrisa ni con las manos. Parece no desear que se le arrulle o coja en brazos. Parece no necesitar, "pasa» claramente de su entorno y también de nosotros si somos los observadores. La retracción autista aceptamos que debe ser considerada como una conducta defensiva o de evitación ante el temor. El problema es que una vez adquirida y dada su eficacia es dificil de modificar. Es, por sus caracteristicas, una de las actitudes que más favorece la detención de desarrollo. Diriamos con Piaget que un mundo sin objetos no permite el desarrollo.

\section{El descubrimiento de las conductas contrafóbicas}

Un sujeto con una gran ansiedad, aparte de desaferentarse y aislarse puede encontrar otros mecanismos para tranquilizarse o disminuir su angustia. El niño autista hace uso y abuso de mecanismos que el lactante normal encuentra también el primer año de vida. Krakenberg en un estudio de población en Suecia, describe que sobre el 80 por 100 de los niños menores de un año han realizado, o realizan, conductas autoestimulatorias: balanceo, cabeceo, chuparse el dedo, tirarse o enrollarse el pelo, manipulación rítmica de genitales, bizquear, etc. Desde los estudios de Spitz, numerosos trabajos han confirmado la relación entre falta de estimulación ambiental y autoestimulación manifiesta. En el estudio sueco con niños normales y supuestamente bien atendidos estas conductas aparecían especialmente en el segundo semestre y casi siempre como un procedimiento que el niño encuentra para conciliar el sueño. En trabajos de Lelord, a nivel de EEG, se describe que el patrón eléctrico durante la autoestimulación es similar al de la primera etapa de inducción a sueño y que la receptividad a los estímulos externos disminuye considerablemente.

El niño autista, decíamos, encuentra también este mecanismo y hace uso de él con más frecuencia e intensidad que el niño normal. Si 
Krakenberg habla de una curva de extinción normal después de los 18 meses, en el autista perdura y se extiende a una buena parte del día. Conductualmente podemos señalar que ha encontrado un nuevo mecanismo para evitar estímulos fóbicos y al mismo tiempo un comportamiento que objetivamente disminuye el nivel de ansiedad.

Algo similar se observará con la autoagresión. En los estudios de desarrollo se describe que en niños normales aparecen autoagresiones. Habitualmente entre los nueve meses y los dos años y medio, y relacionados con manifestaciones conductuales de sentimientos de frustración o rabia. Creemos que en el autocastigo hay un componente autoestimulatorio, que transforma ansiedad en dolor o similar y otro de carácter operante de llamar la atención. Dejaremos este último aspecto para más adelante ya que creemos que todas las conductas del autista tienen un aspecto operante, actúan sobre un medio que responde a ellas y que por desgracia casi siempre estas respuestas son inadecuadas y contribuyen a mantener la conducta. Las autoagresiones son entonces también un mecanismo contrafóbico que encuentra el niño y que incorpora a su repertorio, a veces en forma tan compulsiva que pueden constituir el elemento clínico más notorio, el mayor impedimento para el desarrollo y la clave comportamental más alterada con los padres.

\section{La estructura atípica o disarmónica}

A nuestro entender casi todos los autistas que vemos son disarmónicos. Es raro que nos encontremos con un bebé que no pueda o no "quiera» crecer y con una adecuación total a esa edad donde se detuvo. Prácticamente todos presentarán áreas más desarrolladas. Creemos que el paradigma básico es el mismo. El niño «aprende» en un funcionamiento fóbico-paranoide y por evitar lo temido desarrolla conductas peculiares, etc. No descartamos, como veremos en el esquema, que constituyan el desarrollo de áreas sanas o compensatorias, no comprometidas por la enfermedad y donde se ha podido dar un paradigma de aprendizaje y desarrollo normal. Pero nos inclinamos más por una hipótesis mixta, donde el desenvolvimiento de estas conductas están influidas significativamente por un aprendizaje por reforzamiento negativo.

De lo más característico en el niño autista, es la estructuración obsesiva. Para Hamblin, otro de los comportamientos de llamar la atención. Para nosotros es, sin descartar los aspectos operantes, quizá la única forma de estructuración de los patrones comportamentales en estos niños.

Observamos la estructuración obsesiva en casi todos los autistas. En los más inmaduros o graves, como simples esbozos en la resistencia al cambio, en la tendencia compulsiva a la reiteración y obstinación. En los más avanzados, en lo que puede ser un código claro de 
estímulos y respuestas, de hábitos y apetencias, que buscamos afanosamente en la historia clínica junto con los padres. En algunos ha llegado a ser la base de un intercambio conductual con sus familiares y para nosotros una de las herramientas básicas para el tratamiento.

\section{LOS ASPECTOS OPERANTES DE LAS CONDUCTAS DEL AUTISTA O LA REPERCUSION DE ELLOS EN LA INTERACCION CON LOS FAMILIARES}

La retracción autística, las conductas contrafóbicas y las estructuraciones obsesivas por sus características señaladas de disminuir el nivel de ansiedad, tienden por si solas a perpetuarse. Sin embargo, el niño autista, más allá de lo descrito, no está solo, ni vive solo. Sus conductas son captadas por sus familiares y se responde ante ellas. Son conductas que operan un cambio en el ambiente o en otras palabras como muchas veces se ha dicho es imposible no prestar atención a un niño que se autoagrede, que se balancea, que no se acerca y que nos sorprende mil veces por lo inesperado de su comportamiento.

\section{Patrones de respuesta de la madre o familiares}

Se ha descrito clásicamente dos tipos de madres que "generarian» autismo. De una parte aquellas que por su frialdad, distancia, insensibilidad a los estímulos del bebé, extinguen en él la conducta de búsqueda o acercamiento. En otro punto estarían aquellas que por su ansiedad se anticipan en tal forma a las apetencias o deseos del niño que no dejan que las señales se desarrollen. Bethelhein diría que impiden la creación de un espacio de comunicación entre el bebé y el adulto. Ambas hipótesis se acercarían a comportamientos propios de la madre, marcados por su propia patología y que contribuirían a la génesis del autismo en edades muy precoces. No compartimos totalmente estos planteamientos, aunque hemos observado una minoria de cuadros con una y otra característica. Vemos con más frecuencia lo que describe Hamblin y que puede resumirse en que la madre o similar desarrolla un repertorio conductual variado ante el niño autista, cuya característica central es el desconcierto ante las claves que emite el niño y donde se pierde la interacción armónica entre ambos.

Se pierde o se carece de la capacidad de decodificar los estímulos del niño y se llega a un patrón de respuestas totalmente inconsistentes. Se presta atención a los comportamientos bizarros o de llamar la atención (reforzándolos) y se ignoran los desenvolvimientos adaptativos. Se pasa a veces rápidamente, del esfuerzo continuo de lo patológico, al abandono, se usa el castigo, el grito o el descontrol y el niño termina riendo. Satisfecho aparentemente, como aquel sujeto que tiene mucho miedo y se tranquiliza provocando el terror en los demás. Una 
pauta de respuesta caótica de parte del adulto no da seguridad al niño, aumenta su angustia y refuerza el funcionamiento paranoide en que la madre será casi siempre un objeto peligroso y persecutorio.

Aceptamos entonces que la patologia de la madre es importante pero se concreta ante ese niño, que por un potencial peculiar es capaz por sí mismo de hacer aflorar en ella un patrón de respuesta que con frecuencia otro de sus hijos no despierta.

La madre pierde el desarrollo del niño, a veces exige por encima de sus posibilidades $y$, un poco después, le trata como un bebé. Se anticipa a sus deseos sin ninguna clave propia del pequeño, o se aleja cuando realmente éste inicia su acercamiento. La madre o padres contribuyen de hecho a través del patrón de refuerzo a la manutención del cuadro, tanto en sus aspectos deficitarios, como en sus conductas bizarras. Es obvio que no es un pronóstico de los padres que los hechos se desarrollen de esta manera, ni creemos que consistentemente podamos aceptar, en nuestra experiencia, que sea esta conducta materna la manifestación inconsciente de un deseo de mantener al niño, como a un bebé extraño. Observamos aspectos de este tipo, pero nos cuesta dilucidar si este tipo de fantasías maternas son previas al cuadro o desencadenadas por él.

Vemos entonces que en la manutención del comportamiento del niño autista, influyen factores propios del niño que van desde lo deficitario al autorrefuerzo que encuentra en sus conductas contrafóbicas y elementos propios de la interacción patológica con sus familiares ya sea por patología propia de los adultos que le rodean o por su pauta de interacción que se ha creado.

Creemos que el elemento central del cuadro es la detención del desarrollo armónico, tanto en los desenvolvimientos por áreas, como en el aspecto emocional. Hay un potencial genético que no puede darse más allá de las conductas de déficit o de exceso que delimitan el cuadro. La recuperación del ritmo y estructuración evolutiva debe ser el eje central del tratamiento.

\section{Referencias}

Bethelheim, B.: «La fortaleza vacía. Autismo infantil y el nacimiento de Self». 1967.

Hamblin, R., BuCKholdt, D., Blackwell, L.: «Los procesos de humanización». Fontanella, 1976.

KANNER, L.: "Autistic disturbances of afective contact». Nerv. Cbild, 1943.

Kracherberg, G.: «Aprospective longetudinal study of Children». Acta Pediatr. Scand. Supl. $224,1971$.

LELORD, G.: "Comparative Study of conditioning of averagedevorek responses by coppling sound and light in normal and autistic children'. Psycbopbysiology, 1973, vol. 10 (415-425).

PlaGeT, J.: «Six études de psychologie». Ed. Gautier. 1964.

POPPER, K.: «Objetive Knowledge, an evolutionary approach». 1972.

RimLAND, B.: «Infantile autism». Nueva York, 1964.

RUTTER, M.: «Psychotic disorden in early childhood». Ashford: Headley, 1968.

SPITZ, R. y WOLF, K.: «Anaclitic depression». Psycb. study cbild, 1946. 